\title{
FOOD INSECURITY AMONG NEWCOMER REFUGEES \\ IN CANADA
}

\section{A LITERATURE REVIEW}

\author{
By \\ Mohammad Shafique
}

BA. University of Nangarhar, 2005; MA. Karlstad University, 2012

\author{
A Major research paper \\ presented to Ryerson University \\ in partial fulfillment of the requirements for the degree of \\ Master of Arts \\ in the program of \\ Immigration and Settlement Studies
}

Toronto, Ontario, Canada, 2019

(C) Mohammad Shafique, 2019 


\section{AUTHOR'S DECLARATION}

I hereby declare that I am the sole author of this MRP. This is a true copy of the MRP, including any required final revisions.

I authorize Ryerson University to lend this MRP to other institutions or individuals for the purpose of scholarly research.

I further authorize Ryerson University to reproduce this MRP by photocopying or by other means, in total or in part, at the request of other institutions or individuals for the purpose of scholarly research.

I understand that my MRP may be made electronically available to the public.

Mohammad Shafique. 


\title{
FOOD INSECURITY AMONG NEWCOMER REFUGEES
}

IN CANADA

\author{
Mohammad Shafique \\ Master of Arts 2019 \\ Immigration and Settlement Studies \\ Ryerson University
}

\begin{abstract}
:
In Canada, grocery stores and supermarket shelves display a wide variety of food for consumers. However, newcomer refugees face different challenges in terms of the availability and accessibility of sufficient, nutritionally adequate and culturally familiar foods for consumption upon arrival to Canada that interrupt their integration process in a new society.

This study will provide a review of the literature on food insecurity among newcomer refugees in Canada from 2009-2019. This review, demonstrates that refugees in Canada suffer higher incidents of food insecurity than immigrants and Canadians. Existing research also indicate that food security in the case of refugees need to be perceived more than availability and accessibility of safe and nutritious foods, require provision of culturally acceptable foods. Access to culturally familiar foods may not be possible in many instances, but the negative effects of such challenges put refugees in situations of stress and anxiety in their new home.
\end{abstract}

Key Words: Newcomer; Refugees; Settlement; food insecurity; food security; food availability; accessibility; culturally acceptability. 


\section{Acknowledgment}

I would like to pass my gratitude to all people who helped me complete this MRP, particularly to the honorable Dr. Mustafa Koc for his insightful and valuable advice, guidance, comments and supportive feedback throughout the development of this Major Research Paper (MRP). Dr. Mustafa Koc is a dedicated person who always encouraged me in the pursuit of excellence in my future life in Canada.

In addition, I would like to thank Professor Dr. Amina Jamal for being a $2^{\text {nd }}$ reader. Her comments and supportive feedback during her course work motivated me to work hard.

I would like to thank my family, friend, classmates and instructors; specially my father and mother for their unconditional support from my childhood until today. Lastly, I would like to thank my spouse 'Sitara Tasmim' who has been covering all house related tasks; such as cooking, laundry and working with kids that created an opportunity for me to complete my degree.

Thanks. 


\section{Table of Contents}

AUTHOR'S DECLARATION FOR ELECTRONIC SUBMISSION OF A MRP...... ii

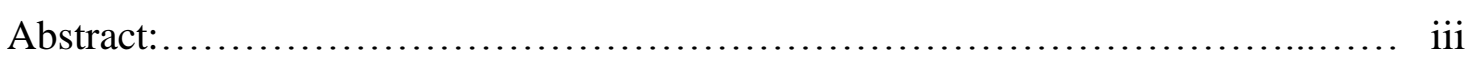

Acknowledgment: .................................................. iv

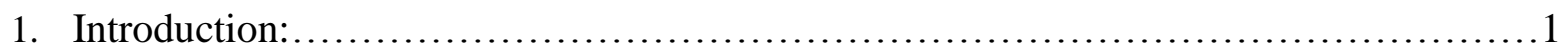

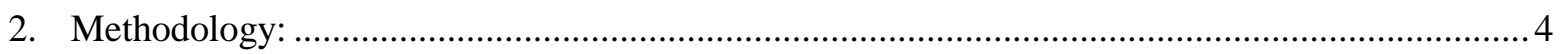

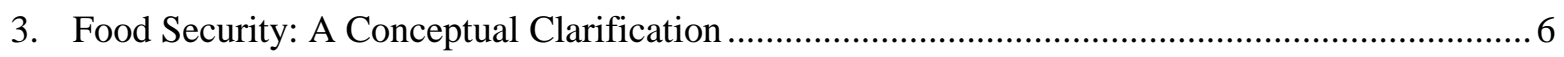

4. Newcomer Refugees and Challenges of the Settlement Process in Canada: .............................. 10

5. Food Insecurity among Refugees in Canada: A Review of Literature...................................... 14

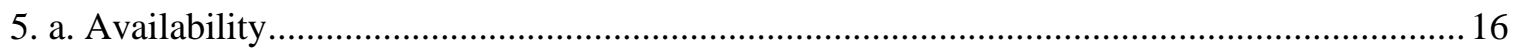

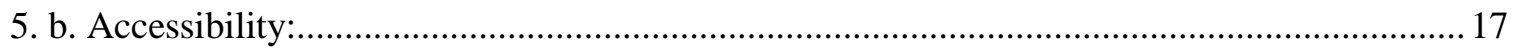

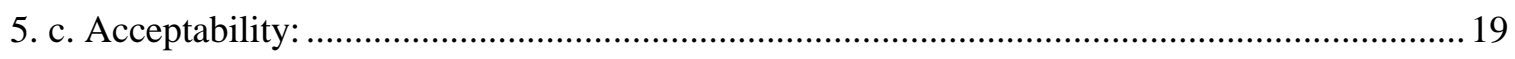

Challenges for Accessing Culturally Acceptable Foods for Refugees: ..................................... 22

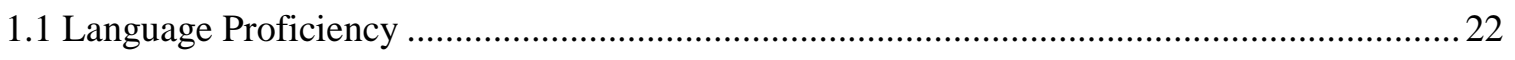

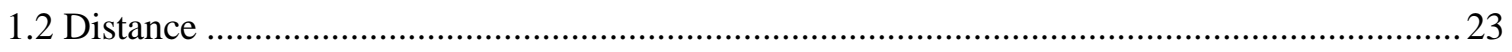

1.3 High cost of living combined with lack of affordable housing:............................................. 24

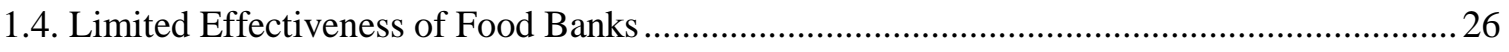

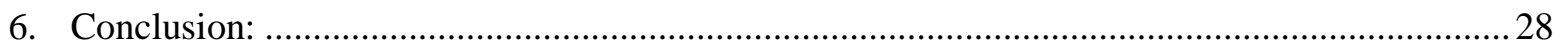

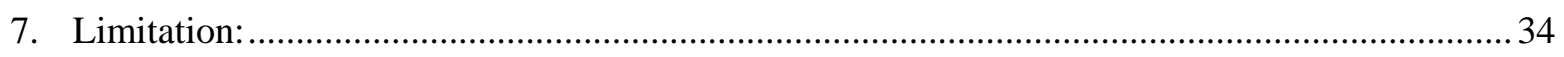

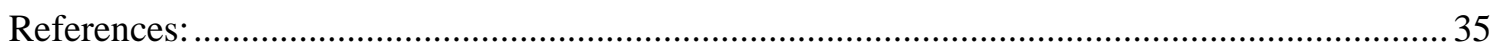




\section{Introduction:}

Food is not only an essential of human life and health, but it is also a vital component of culture. Food is a significant bond that brings family members together around the table (Koc, Soo, and Liu, 2015). Food is something that denotes identity and membership to a social group and is also a marker of social status (Soo, 2012). Not only does food define our identity, but it also shapes our physical, mental, social, and economic existence (Shiva, 2013). Food is a fundamental human need and 'food insecurity,' is considered as a violation of human rights (Human Rights, 2010; WHO, 2015). The right to food is described by the United Nations as a public health issue, as food insecurity affects both adults and children - with outcomes of poor health that often affect the mental and physical health of people, which causes stress and other chronic diseases.

According to Koc, Soo, and Liu (2015), food security is an essential marker of a successful settlement process. Unfortunately, many newcomers to Canada do not have sufficient income to purchase healthy, nutritious, and culturally acceptable food. Access to culturally acceptable food is an essential concern for newcomers to feel at home (Soo, 2012; Moffat, Mohammed \& Newbold, 2017). Especially for highly traumatized populations such as refugees, who have recently lost their ties to their homeland, and suffered prolonged periods of extreme food insecurity as internally displaced people (IDPs), or as refugees living in camps. Despite all other issues, food insecurity in the destination country becomes an essential reminder of the past vulnerabilities that newcomer refugees had suffered.

In recent years, most refugees in Canada have arrived from poorer developing countries, particularly from Latin and Central America, Asia, Middle East, and Africa-yet these refugees are also raised in rich cultures culinary, wherein food is a primary aspect of their identity and ethnic heritage.

In Canada, newcomer refugees typically start with limited income and struggle to make ends meet. Upon arrival, most refugees are looking to find affordable housing, especially in coethnic neighborhoods, with an established diaspora. Unfortunately, many of these neighborhoods

in Canada are 'food deserts,' which are areas that face food insecurity through 1) a shortage of ethnic food grocery stores, and 2) a lack of adequate income that makes ethnic, cultural food inaccessible. 
Many studies across Canada have discussed the existence of food insecurity among newcomer refugees in terms of availability and accessibility. However, there are still gaps in research addressing the acceptability of food for recently arrived refugees-particularly about culturally and socially accepted food from their home country. To address the gap, this Major Research Project focuses on food insecurity, particularly the challenges of culturally accepted food in the context of integration in the new society. This paper critically analyze the literature have been done on food security among newcomer refugees and immigrants in the last ten years between 2009 2019. To understand what literature exists and indicate the significant challenges and barriers to cultural food for newcomers in Canada.

Food insecurity could affect refugees' integration process in society for several reasons; that could influence newcomers' identity formation and feeling of belonging in Canada. The literature has noted the importance of food on identity that food is both physical and symbolic of culture (Soo, 2012). Meanwhile, food conveys meaning to others and ourselves about identity that who am I. Socially isolation makes it difficult for refugees to feel home or valued to be able to integrate into Canadian society. It is not only in adults, but children also experience a sense of marginalization if they are not able to obtain sufficient and culturally acceptable food.

Lack of income can lead refugees to food insecurity, which causes poor health and chronic diseases. Poor health prevents newcomer refugees from being able to keep gainful employment. Because of such factors contributions newcomer refugees feeling exclusion from the host country social life. However, such experience could alarm that many newcomer refugees are food insecure.

This study has been designed in different chapters. The methodology chapter is discussing the framing and physical shape of this study. Such section clarifies how this study conducted and what sources used to find the barriers and challenges regarding food security among newcomer refugees in Canada. The conceptual clarification of food security and problems is discussed in chapter three that arise the consumption of inadequate food among newcomer refugees in Canada. Chapter 4 introduce newcomer refugees and their settlement challenges in Canadian society. Evidence from literature indicates that upon arrival, most refugees have language barriers even though they are well educated. Because of language issues, employers only hire them in low-wages positions (Huang, 2014). It is also noted that in Canada, people who do not know English or French may not qualify for a better paying job that can contribute to alleviating food insecurity. 
Chapter 5 is the main body of this study highlights the barriers and challenges that newcomer refugees face with respect to nutritious and healthy food. Newcomer refugees experience food insecurity because of different circumstances such as lack of language proficiency, lack of cultural food, a long distance from the supermarket or ethnic food stores, high cost of living and lack of affordable housing and less effectiveness of food banks.

Food insecurity has a broader connection to economic and social circumstances that lead newcomer refugees to the point of being food insecure (Soo, 2012).

Chapter 6 provides a conclusion and summarize some of the gaps, challenges, and opportunities in applying this framework for the holistic measurement of food insecurity among refugees. In this part, the evidence and information provided by scholars and researchers in the last ten years are discussed. Meanwhile, it is also notable that such a phenomenon is not only real for adult refugee household members but also that their children also face such challenges that can be considered food insecurity issues in Canada.

Most articles reviewed were in English that discussed the causes of food insecurity among refugees and immigrants. The bibliographies of selected articles were reviewed, analyzed, and sorted into the categories of availability, accessibility, and acceptability.

The conclusion provides some policy recommendations for the federal government to address food insecurity concerns among refugees. At the end limitations of this study is lack of time and sources that I did not have to conduct interviews. Therefore, the study leads me to conduct further research in the future. 


\section{Methodology:}

This is an exploratory research paper. As Reiter (2017) suggests, exploratory research method is used "to investigate a problem that is not clearly defined". For this kind of research, a researcher starts with a general idea and uses his critical lens as a medium to identify issues that will inform future research. Exploratory method involves an in-depth literature review of different academic articles, journals, and published reports related to the researcher's chosen issue, examine data sources, interviews key experts in the field and may involve a small-scale qualitative and quantitative research to develop an awareness of the key research questions (ibid).

While I initially planned to include a number of interviews with a number of Afghan refugees living in Toronto, due to time concerns, and potential difficulties in completing ethics review that is needed for this process, I ended up limiting my research to a literature review. In my review of the literature, I also wanted to gain insights on the causes and consequences of food insecurity within the Canadian context and among newcomer immigrants. This was followed by a more targeted review of the literature on conditions of food insecurity among newcomer refugees in Canada.

Most studies on food insecurity focus on availability and accessibility of food among newcomers. I am particularly interested in looking at limitations in accessing "culturally acceptable foods" among newcomer refugees as a challenge not only in terms of food security but also as an important obstacle in their successful settlement in Canada. To address these concerns my literature review specifically targeted conditions of availability and accessibility of culturally acceptable foods. I limited my literature review to publications and research reports from 2009 to 2019 to look at recent developments in conditions of food insecurity among refugees in Canada.

My literature review included several relevant studies on immigration and food insecurity in academic articles, books, conference proceedings, newspapers, trade magazines, and reports. I used multi-disciplinary search engine Google Scholar, Ryerson University's online library archives, and several social science databases such as ProQuest. I focused the search on the following key terms: "food security," "food insecurity," "refugee," "asylum seeker," "immigrant," "availability," "accessibility," and "culturally familiar food" "acceptability." In this research, the word 'newcomer' is defined as "people who have arrived in Canada during the last 10 years." 
The methodology in this paper has been designed to examine the question of cultural acceptability of food in the new society, in order to discuss the cultural challenges that newcomer refugees face when dealing with access to food in Canada. 


\section{Food Security: A Conceptual Clarification}

The concept of food security was first developed in the 1970s, with the primary focus on food supply problems - particularly on the availability and accessibility of enough food to cover global and national needs (Soo, 2012). Although there have been various definitions of food security over the years, the definition adopted by the Food and Agriculture Organization of the United Nations (FAO) at the World Food Summit in 1996 is quite commonly used. According to this definition, food security refers to "a situation that exists when all people, at all times, have physical, social and economic access to sufficient, safe, and nutritious food that meets their dietary needs and food preferences for an active and healthy life" (Soo, 2012; Sundaram, 2012; Tarraf, Sanau and Giroux, 2017; Koc, Soo, Liu, 2015; WHO, 2015).

In the 1980s and 1990s, the focus of food security shifted from the global and national level in dealing with hunger and food crises, to the household and individual levels, looking deeper into obstacles with the availability and accessibility and food consumption at the household level (Tarraf, Sanau and Giroux, 2017). Kohen (2010), for example, defines food insecurity as

"the limited, inadequate or insecure access of people and households to sufficient, nutritious, safe, personally acceptable food, both in quality and quantity, to meet their dietary requirements for a healthy and productive life" (p.13).

Similarly, food insecurity is perceived as limited access to sufficient, safe and nutritious food. (Moffat, Mohammed \& Newbold, 2017; Soo, 2012, Koc, Soo \& Liu, 2015). Several factors and barriers that leads to food insecurity, ranging from famines, to armed conflict, but the most prominent factor is lack of access to means of production to produce or lack of income to purchase food to feed members of the household. Competing priorities such as housing, health or school expenses may also limit available funds to purchase food, especially for the urban dwellers who rely on markets to feed themselves. In many instances, aid or social assistance programs run by international and national organizations, governmental bodies and civil society organizations and charities may assist those suffering food insecurity. However, rising demand for these services or cuts in social programs would also lead to rise in food insecurity among the most vulnerable groups such as people live in poverty, unemployed, underemployed, elderly, racialized minorities and immigrant and refugees. 
There are two types of household food insecurity: 1) chronic and 2) transitory. 'Chronic' food insecurity deals with poor diet for a prolonged period of struggle among the household to purchase necessary food, while 'transitory' food insecurity focuses on a temporary decrease in access to the food needed by household due to instability; of food prices, income, or even seasonal food supply (Chávez, 2015). Food insecurity is also accompanied with acute or chronic nutritional deficiencies and related physical, mental, health problems (Tarraf, Sanau and Giroux, 2017; Koc, Soo, Liu, 2015; Bidwell, 2009). Individuals in food insecure households are reported to have three times higher odds of suffering major depression (Kohen, 2010), which is a debilitating psychological condition that is serious enough to be a type of chronic disease.

Food insecurity continues to be a pressing problem - mostly in the developing countries, but even in advanced industrial countries such as Canada, as a significant portion of the population suffer from food insecurity suffer higher rates of food insecurity in comparison to non-immigrants and immigrants who arrived earlier. Vulnerable groups include those people who are living in poverty, seniors, and people living in social assistance, indigenous populations, and other racialized minorities (Tarasuk, Dachner \& Mitchell, 2019). In particular, the greatest relevance to this study is the research in the literature on newcomer refugees who recently arrived in last decade that indicates how refugees access to culturally acceptable food. According to the Canadian Community Health Surveys conducted by Statistics Canada (2012), 12.4\% of the Canadian-born population suffer food insecurity. According to Tarraf, Sanau and Giroux (2017) the prevalence of food insecurity was higher among recent immigrants $19.6 \%$ percent, compared with non-recent immigrants 11.8 percent and the Canadian-born population 12.4 percent.

Newcomer refugees who have less than ten years in Canada have a higher prevalence of food insecurity than both the general Canadian population and previously settled immigrants (Tarasuk, Dachner \& Mitchell, 2019). Higher levels of food insecurity are attributed to a variety of challenges, such as difficulty in entering the Canadian labour market. Other factors such as, high cost of living, especially due to lack of affordable housing in major Canadian cities; difficulty in purchasing traditional or culturally acceptable foods; limited information about shopping and cooking options; changes in lifestyle; and lack of language proficiency are also factors behind higher incidents of food insecurity among refugees (Soo, 2012; Koc, Soo, Liu, 2015). Research indicates that all the above factors are common among newcomer refugees in different cities of Canada. 
Several studies have been conducted in different cities regarding food insecurity among newcomer refugees (Lane, Nisbet, Vatanparast, 2019; Ennab, 2017; Vahabi and Damba 2013; Ambtman, \& Ali, 2009; Carter, \& Osborne, 2009; Zurba, et al. (2012). After realizing these adverse effects, the Canadian government took serious action to conduct further research on food insecurity. A formal recognition of food insecurity has now been enshrined in several high-level federal programs, e.g., Canada's Action Plan for Food Security and by federal government departments such as Agriculture and Agri-Food Canada, Health Canada, and Public Health Agency of Canada (Soo, 2012, p. 8). Government and local agencies have laid out the main components that are necessary to reduce the level of food insecurity in the country, adapting their policies to meet the needs of Canadians regarding insecure food.

It is important to note that the foundational concept of 'food security' has been highly debated, with disagreements in conceptualization seeming to be quite frequent. Even FAO tends to revise its conceptual framework and indicators, which indicates four factors used to measure food security. The Ryerson Centre for Studies in Food Security (CSFS) has identified five key components of food security: 1) availability, 2) accessibility, 3) adequacy, 4) acceptability, and 5) agency (Soo, 2012). In this study, I am going to use these components particularly availability and accessibility of cultural food as key factors in defining and measuring food insecurity among newcomer refugees.

The 'availability' of food refers to the sufficiency in appropriate quantity and quality of food, enough to nourish the entire population (Tarraf, Sanau and Giroux, 2017; Bidwell, 2009). Meanwhile, the 'accessibility' of food deals with how all members of the society are able reach out to the available food. Availability is more of a supply issue, whereas accessibility deals with the questions of distribution and the social conditions that determine access to food, e.g., income levels, affordability of food, distance to food outlets, transportation, and distribution of food services to vulnerable segments of the society (Koc, Soo, and Liu, 2015).

While almost all food security definitions include 'availability' and 'accessibility' as metrics, the other components used by the CSFS point out the factors that go beyond these common concerns. The third component, 'adequacy,' deals with the nutritional qualities, safety, and the ability for individuals to make healthy food choices in their local environments (Kohen, 2010). A fourth component of food security, 'acceptability,' is especially important for newcomers, 
referring to individuals' access to culturally familiar foods and access to food in a dignified manner. This concept, which was underrated in the literature, is one of the focuses of this MRP.

The final component of food security identified by the CSFS is 'agency,' which deals with the capability of individual and social actors to provide the conditions for food security in the society at large. This includes families, the broader food environment, the private sector, civil society, and governmental actors (Centre for Studies in Food Security, 2012; Koc, Soo, Liu, 2015; Soo, 2012). To address this component, the government needs to develop overarching policies regarding food and food security that are robust enough to meet the needs of everyone who resides in their country. 


\section{Newcomer Refugees and Challenges of the Settlement Process in Canada:}

A refugee is someone who has been forced to flee his or her country because of persecution, war or violence. A refugee has a well-founded fear of persecution for reasons of race, religion, nationality, political opinion or membership in a particular social group. Most likely, they cannot return home or are afraid to do so. War and ethnic, tribal and religious violence are leading causes of refugees fleeing their countries (UNHCR, 2018).

Beyond the UNHCR refugee definition, Oda et al. (2019) highlight that the Canadian government interprets a refugee as "a person who has a greater need of protection than other applicants because of particular circumstances that give rise to a heightened risk to their physical safety or well-being" (p. 441). In addition to the above interpretation, the Canada Immigration Act of 1976 defines refugees as a special class of immigrants and fully recognized as convention refugees (Wilkinson \& Garcea, 2017; Oda et al., 2019). Based on the Canada Immigration Act of 1976 and signatory of the 1951 Convention of Refugees, Canada is a country that accepts refugees from different parts of the world, and works closely with UNHCR and other refugee resettlement agencies.

Based on Immigration, Refugees and Citizenship Canada (IRCC)'s most updated information, Canada is a country that hosts refugees under two major programs: 1) government and private sponsorship; 2) asylum seekers, refugee claimants and humanitarian resettlement program (alongside UNHCR, this program considers people for resettlement after passing the medical exam, undergoing a security check up, and provide a criminal background certificate from a different place they were residing for more than six months) (Murdie, 2010; IRCC, 2018). Asylum seekers are a particular group, referring to people who cross the border and enter into Canada without refugee status, and then file a claim adjudicated in Canada (Wilkinson \& Garcea, 2017; Oda et al., 2019; UNHCR Canada, 2018).

Before discussing the application process for asylum seekers, it will be helpful to know how the international agencies define this category of people. UNHCR (2018) defines 'asylum seekers' as

When people flee their own country and seek sanctuary in another country, they apply for asylum - the right to be recognized as a refugee and receive legal protection and material assistance. An asylum seeker must demonstrate that his or her fear of persecution in his or her home country is well-founded. 
In Canada, the process for accepting an asylum claim takes months and sometimes years, but meanwhile, according to Immigration, Refugees and Citizenship Canada (IRCC), they are eligible to work, attend school, and receive medical care (Murdie, 2010). Whenever their claim accepted, they can apply for permanent residence and add family members to their application (Wilkinson \& Garcea, 2017). While getting their permanent residency, their family automatically becomes eligible to attain Canada refugee status (Murdie, 2010; IRCC, 2018).

In between navigating such difficult administrative processes, most asylum seekers experience settlement and integration-related challenges. Because of having no proper documents, they cannot easily rent a house and face issues finding affordable housing, which is necessary due to lack of income, unemployment, language proficiency, and lack of culturally acceptable food. All of these factor affect their ability to acquire sufficient, safe, and nutritious food to sustain a healthy and active live (UNHCR, 2018; Adekunle, Cidro, \& Filson, 2015; WHO, 2015).

The second well-known program for accepting at-risk immigrants is the 'refugee sponsorship program,' e.g., the Government-Assisted Refugee (GAR) and Privately Sponsored Refugee (PSR) programs. GAR is a program that selects refugees from overseas - either with the assistance of the United Nations High Commissioner for Refugee (UNHCR, 2018) or other refugee supporting agencies - with direct contributions from the Government of Canada (Wilkinson \& Garcea, 2017). This type of refugee receives financial support for up to one year (Canada, UNHCR 2018). In addition to this financial support, they may also receive assistance in acquiring accommodation, clothing, food, and employment-related and other resettlement assistance (IRCC, 2018). Finally, another Canadian refugee-accepting program is called "family reunification," allowing Canadian immigrants to sponsor their own family members through a specific refugee status program (IRCC, 2018). After submitting the application, the Canada government investigates the eligibility of the sponsored person or family member (Murdie, 2010; IRCC, 2018). After finding them as eligible, the government issues refugee status and allows them come to Canada.

Both PSRs and GARs receive their permanent residency upon arrival at the first destination (Wilkinson \& Garcea, 2017) and both receive free settlement services from agencies funded by the Canadian government (Oda et al., 2019; IRCC, 2018). In this initial stage, refugees may face many challenges, including food security, through different integration factors. The key barriers to refugee integration in the labour market are language proficiency, education, and cultural- 
related concerns (Wilkinson \& Garcea, 2017). At first, most refugees do not know how to speak the English or French languages fluently, even though they are well educated. Initially, because of language problems and lack of Canadian experience, many employers will only hire newcomers in low-wage positions, involving physical labour jobs such as dishwashing, cleaning, and factory work (Huang, 2014). According to Adekunle, Cidro, \& Filson, (2015), these physical jobs keep them busy and do not allow them to interface in "social interactions and do not offer the opportunity to practice English on a daily basis with co-workers in job site" (p. 4).

In Canada, people who do not know English or French may not qualify for a better-paying job that can contribute to alleviating food insecurity (Huang, 2014). Adekunle, Cidro, \& Filson, (2015) states that $65 \%$ of refugees who arrive to Winnipeg within the last five years do not know English or French. Some findings illustrate that, upon arrival, most refugees are primarily looking to find co-ethnic neighborhoods for them to live (Oda et al., 2019). Yet in co-ethnic neighborhoods, it is considerably more difficult for newcomer refugees to improve their English and French language proficiency, because they will be able more easily get by with their own language.

Because of these significant language and labour-market challenges, many refugees must rely on government social assistance, which means that their level of income will be at or below the poverty line (Adekunle, Cidro, \& Filson, 2015). This is why private sponsorship supports can be so important. Those Canadians who are sponsoring their relatives are responsible for providing immediate assistance such as providing shelter, settlement assistance, and financial support for several months - until the refugees have somewhat adjusted to life in Canada and are ready to integrate in the labour market and become self-sufficient (Tarraf, Sanau and Giroux, 2017; Huage, 2014).

Likewise, regarding refugees' health issues, Simich, Este, \& Hamilton, (2010) argues that most refugees in Canada experience poor health and psychological distress that result from economic difficulties. Therefore, by experiencing economic hardship through inadequate income to cover living expenses, refugees are particularly vulnerable to a lack of access healthy food. In addition, many recently settled refugees are also faced long distances away from culturally acceptable food markets (Qadeer, Agrawal, \& Lovell, 2010). The high costs of public transport and lack of time to go to ethnic stores acts as a strong deterrent; thus, they are not motivated to acquire fresh, healthy and culturally acceptable food from stores (Moffat, Mohammed \& Newbold, 2017). 
In this study, three different components of food security are considered as primarily important issues for refugees: 1) food availability, 2) accessibility, and 3) acceptability among newcomer refugee households. To address the current gap in the literature on these aspects of food insecurity, this dissertation will primarily focus on the challenges regarding cultural acceptability of foods among newcomer refugees.

Canada is a popular destination for immigrants, and their integration is a central strategy for the country's demographic growth and economic development. Since 1988, Canada has welcomed an average of 230,000 immigrants per year (Edmonston, 2016). In present times, approximately 250,000 new immigrants are coming to Canada each year - of which 20,000 of them are refugees (Ennab, 2017, p. 1). In 2011, the immigrant population in Canada was approximately $20.6 \%$ of the total population, or roughly 6.8 million people. By 2031, it is expected that the foreign-born population in Canada will be over $25 \%$ of the population (CIC, 2012). Thus, it is important for the government to understand the causes and plan for effective response to existing social problems such as food insecurity for newcomer immigrants and refugees for a successful settlement process. 


\section{Food Insecurity among Refugees in Canada: A Review of Literature}

'Food security' refers to the ability of individuals, households, and communities to get appropriate and nutritious food on a regular and reliable basis (Vahabi and Damba, 2013). Because of household income and integration issues in new society, newcomer refugees in Canada (Moffat, Mohammed \& Newbold, 2017; Soo, 2012) often experience food insecurity. The most important challenge to overcome in a refugee's daily life in Canada is how to acquire food in a new cultural landscape is because of language barriers and lack of Canadian labour market experience (Bidwell, 2009).

Recent studies demonstrate higher incidents of food insecurity among newcomer immigrants and refugees and ethnic minorities in Canada (Soo, 2012; Bidwell, 2009; Vahabi and Damba (2013); Vahabi et al., 2015; Shiva, 2013; Tarasuk, Mitchel, \& Dachner, 2014; Trinidad, Camden \& Coleman, 2015). Each researcher in the field focuses on different issues, e.g., examining various aspects of the general concept of food insecurity and its barriers among immigrants; how refugees and immigrants reconstruct their food identity in Canada; and how refugees successfully integrate into Canada's different cities.

Some other studies focused on conceptual issues of food security and insecurity, analyzing the components of food availability, accessibility, and cultural acceptability of fresh food. Going beyond issues of food supply chain, they also investigated the psychologically negative aspects of food insecurity among populations, such as stress, anxiety, and other chronic diseases (Huang, 2014; Vahabi and Damba, 2013; Power et al., 2016). Other researchers highlighted the concept of measuring food insecurity among newcomer refugees in 'food deserts' in terms of distance from supermarkets (Behjat, 2012; Joassart- Marcelli et al., 2017; Martin, 2012; Skerrit, 2013). Meanwhile, some others concentrated on food insecurity as a global issue among different minority groups within certain geographic locations or phenomena (Weaver, and Hadley, 2009; Kohen, 2014; Riches, 2016; Tarasuk, Dachner, \& Mitchell, 2019; WHO, 2015; Maynard et al., 2019).

One of the important study to this MRP is the Moffat, Mohammed \& Newbold (2017) who conducted research about the cultural dimensions of food insecurity among immigrants and refugees. The objective of their study is the influence of culturally familiar foods among refugees and immigrants in Canada. The study focuses on food availability, accessibility, and cultural acceptability. Their findings illustrate importance of cultural factors and difficulties created 
refugees' food preferences in terms of the three pillar: availability, accessibility and the use of culturally acceptability of new food varieties that forcing them to rely on other solutions such as canned and frozen food, which disrupt cultural values about food consumptions. In addition, the study indicates that in urban area cultural food are available in supermarkets and ethnic stores, which is not perceived as familiar, fresh tasting, less processed and safe food. Meanwhile study indicates that organic food is available but due to high cost in combination with low-income is a major barrier for access. Moffat, Mohammed \& Newbold (2017) added that services provider need awareness and understanding regarding cultural value, concerns and foodways to improve cultural dimensions by providing support to obtain and eat the kind of food that are culturally appropriate for newcomer refugees. The research demonstrates recommendation such as service providers needs to provide immigrants cultural and language appropriate resources and teach newcomers food related information about nutrition and food use in the Canadian context.

Several scholars have also highlighted the importance of culturally familiar foods among newcomer refugees (Hammelman, \& Hayes-Conroy, 2015;Mathew, 2014; Qadeer, Agrawal, and Lovell, 2011; Wiig \& Smith, 2009; Murdie, 2010; Murdie \& Logan 2012; Sherrell, 2009; Carter \& Osborne, 2009; Cowart, 2012 D’Souza \& Jolliffe, 2013). Some other scholars have indicated that, because of limited time and food varieties, food banks have failed to provide sufficient and culturally acceptable food to newcomer refugees and low-income immigrants (Food Bank Canada, 2011; Miller, 2016). Yet despite all these difficulties, upon arrival to Canada, the health of newcomer refugees has been found to be comparable with, and sometimes exceeding, native-born Canadians' health. and that of immigrants who have come to Canada earlier than the last decade (Edmonston, 2016; Food Secure Canada, 2017; Health Canada, 2010; Medrano, 2015; Oda et. al., 2019; Preston et al., 2011; Tarasuk, Dachner \& Mitchell, 2019).

After reviewing such articles, I found that many researchers looked at food insecurity through different lenses. Some scholars observed food insecurity among refugees who are newly settled in high-income and developed countries, especially in Canada. Their findings indicate that poor economic conditions, lack of knowledge on new food, difficulty with shopping, language proficiency, and problems complying with religious food rules or cultural-related issues are the main challenges associated with the occurrence and severity of food insecurity among newcomer refugees (Vahabi and Damba (2013). Worryingly, some newcomer refugees begin to skip meals 
after arrival to new countries, developing dangerous new eating habits to save money, which is a direct pathway into food insecurity (Bedwill, 2009; Koc, Soo, Liu, 2015).

As has been discussed, it appears that the main issues with 'culturally acceptable food' is linked to its availability and accessibility_-both of which are related to newcomer refugee income and lifestyle. Soo (2012) states that finding ways to acquire a proper household income could reduce the risk of food insecurity among refugee families. Yet this would require federal government agencies to develop strong policies for newcomer refugees regarding their income and ability to stay out of poverty. In addition, the government needs to develop a national strategy that should encourage stakeholders to be more accountable for food security in Canada. Stakeholders, such as food suppliers, also need to provide different types of food in their outlet to increase the food availability for newcomer refugees, as will be discussed further in the next section.

\section{5. a. Availability}

'Food availability' refers to access to an adequate quantity of healthy and affordable food to satisfy newcomer refugees' needs (Moffat, Mohammed \& Newbold, 2017). Food availability addresses the question: "Is there enough food to feed everyone?" Overall, most Canadian supermarkets and grocery stores are stocked with a wide variety of food. Besides maintaining general food availability, the supermarket owners are also trying to increase the proportion of healthy food from "milk to vegetables and meat to maple syrup" in their stores (Soo, 2012). However, due to the unfamiliarity of much of this food, many newcomer refugees become less interested in what is available at supermarkets (Ambtman \& Ali, 2009).

Most newcomer refugees thus begin to rely on neighborhood small convenience or local ethnic stores to meet their food needs-yet, compared to these convenience stores, supermarkets have reserved far greater shelf space to fruits and vegetables (Bedwill, 2009). According to Ambtman \& Ali (2009), availability is limited by the types and prices of food, e.g., healthy foods in the supermarket are much less expensive compared to convenience stores. In addition, the prices of dairy products (e.g., milk, cheese and butter) are also cheaper in superstores.

Because of financial difficulties such as high cost of rents and other home expenses, refugees are unable to reside in urban areas, so they prefer to live in affordable housing in coethnic neighborhoods (Qadeer, Agrawal, and Lovell, 2011; Bedwill, 2009), yet this can put them 
at risk for living in potential food deserts. Vahabi and Damba (2013) highlighted a study participant's answer that touches upon these risks:

"the job pays little and near our place there are not that many big food stores like No Frills [a large discount supermarket]. We do not have a car and have to take the TTC [Toronto Transit Commission] for transportation and that is costly when you have to pay for rent and other bills" (p. 11).

High costs of living eventually lead some refugees to have no proper and permanent resident, which creates a food storage problem; they cannot keep purchased food for long periods and therefore must travel constantly to acquire fresh or non-perishable foods (Ambtman \& Ali, (2009).

For production and trade of adequate food, it is necessary to ensure appropriate food availability and accessibility among recently arrived newcomer refugees and immigrants (Bedwill, 2009), which is particularly difficult for newcomer refugee households with limited income, lack of language fluency, and private transportation who cannot drastically alter their shopping patterns. In these cases, the lack of availability of ethnic food stores is a big problem. Because of cultural norms in their home countries, refugees find difficulties in fully trusting new food varieties, products, and stores. In addition, because of their language problems, refugees cannot always read what kind of ingredients are printed on the labels.

Some studies have found that even when healthy food is available in Canada, newcomers have difficulties in adjusting to new food tastes. Moffat, Mohammed \& Newbold (2017) added one of participant interviewee states: "due to changes in the quality of available food in their new country, they are no longer enjoying eating. " Compared to back home, the different food tastes are unappealing, which is especially concerning among refugee children. Since it takes time to adjust to eating unfamiliar foods, children can accidentally fall into a situation of food insecurity, during a crucial time when they need the proper nutrients to become healthy adults.

\section{5. b. Accessibility:}

Access to food is a basic and fundamental human right. "Inadequate access to food is considered a violation of human rights" (Vahabi and Damba, 2013). De Haen, Klasen, \& Qaim, (2011) added that access to food presents both physical and economic challenges at the household level. 'Physical-access' to food is regulated by the existence of infrastructure at the national and regional level, while 'economic-access' to food is determined by the purchasing power of the 
household, including the existing level of prices. Food accessibility-especially economic access-represents the greatest challenge to food security among newcomer refugees and immigrants in Canada.

Studies indicates that there are three major socio-economic factors that hinder newcomer refugees' access to nutritious and enough food: 1) low-income, 2) long distance to food superstores, and 3) lack of culturally familiar foods (Soo, 2012), i.e., 'food acceptability' (discussed in Chapter 3).

Because of economic problems and difficulties, newcomer refugees experience a particularly complex set of circumstances with respect to gaining income through employment in Canada (Moffat, Mohammed \& Newbold, 2017; Soo, 2012). Such problems could be considered as a lack of Canadian education and, arguably more importantly, Canadian job experience which is considered a big challenge for refugees to access to food. When refugees are looking to find employment, despite their comparable education and work experience, they often have difficulties having their credentials recognized by employers and find it difficult to re-certify due to the high cost of attending post-secondary schools in Canada.

Meanwhile, being in a new cultural environment can also contribute to not being aware of how to access employments and other social support services (Soo, 2012). In addition, discrimination based on race and other prejudice creates a stigma around refugees and immigrants that creates a barrier to entry in the Canadian job market (Martindale, 2014). During times of precarious employment, refugee households must consume less expensive and low-quality food, rather than attaining a sufficient quantity (Vahabi and Damba, 2013). Thus, all problems newcomers face with respect to employment and income directly compromise their access to healthy and quality food (Soo, 2012).

Seasonal employment and precarious working conditions also limit employment income for refugees. Vahabi and Damba (2013) indicate that most refugees are employed in sectors such as construction and gardening, or only work part time. This means that in the winter season, they are more likely to spend time at home and not working (Ennab, 2017). Their income is not always sufficient to cover everything along the year; therefore, they rely on social assistance for subsistence, which is not even sufficient to cover the cost of housing and healthy food (Vahabi and Damba, 2013; Murdie, \& Logan, 2012). 
It is important to understand that 'food accessibility' considers where products are being made and where they are being used; in other words, each part of a food supply chain including the producer, manufacturer, processor, retailer, distributor, wholesaler, and the consumer. Understanding these parts of the supply chain is critical, and it has been traditionally defined by "supply" and "demand" functions that determine what consumer trends are evident (Moffat, Mohammed \& Newbold, 2017).

In terms of refugees, they struggle to find adequate supply for their food needs, as the lack of affordable housing in major Canadian cities push them to rent an apartment outside the urban area, or far from business hubs or supermarkets (Teixeira, 2009). Compared to the overall population, immigrants are more likely to use over 30 percent of their household income on paying house rent, even when paying rents considered "affordable housing" (Preston et al, 2011; Soo, 2012). According to Preston et al. (2011), if newcomer refugees, asylum seekers, and recently arrived immigrants must spend more than 70 percent of their income on housing, the remaining 30 percent is not enough money to purchase healthy, nutritious and culturally acceptable food, considering other expenses such as transportation, schooling, and other everyday necessities. Housing affordability is another important barrier among newcomer refugees in acquiring adequate culturally acceptable food, especially in high-cost cities such as Toronto, Vancouver, Montreal and Calgary (Rose, 2010).

The problem of affordable housing is directly linked to food insecurity—rent is fixed and must be paid every month, while food intake is a factor that can be adjusted (Soo, 2012). Rose (2010) added that there is a well-known expression regarding affordable housing among newcomer refugees: that "pay the rent off, then feed the kids," is directly linked to food insecurity.

\section{5. c. Acceptability:}

"I have tried to look for foods that I am used to back home, but I have not been lucky. I would like to eat fruits such as guava, papaya, nopales (prickly pear), jicama (Mexican potato). We now mainly eat cereals, pasta, rice, and legumes."

—refugee living in Hamilton, ON (Vahabi and Damba, 2013).

In 2007-08, According to Health Canada (2012), 961,000 of Canadian households were food insecure. The prevalence of household food insecurity was higher among recently arrived refugees and immigrants compared to non-recent immigrant households. 
Before writing about 'food acceptability' it is important to know that the Canadian government has an action plan in place for food security that recognizes the importance of culturally acceptable food (Adekunle, Cidro, \& Filson, 2015). The government has thus taken into account how each refugee household belongs to a rich food culture, which is an important component of their individual identity (Moffat, Mohammed \& Newbold, 2017). This commitment becomes very difficult to fulfill, however, due to the specialized needs of specific cultures within refugee populations, e.g., Muslim refugees who require Halal meat, or Jewish refugees who need to have kosher meat.

Joassart-Marcelli et al. (2017) argues that cultural food acceptability requires "a good system that protects the right of food insecure people, fosters sustainable livelihoods, and addresses the cultural value of food practices" (p. 39). The process of newcomer refugees' integration shows that upon arrival, cultural food supports newcomers' feeling of belonging - helping them to "feel more at home in their new country" (Soo, 2012). As such, global markets have developed widespread supply chains for food to bring cultural favorites from one country to another. For instance, devout Muslims eat halal meat that excludes pork and pork products and other animals are required to be slaughtered according to halal rules (Mathew, 2014). For this reason, they are comfortable eating processed foods as long as the packaging features a Halal label-indicating that the food product is prepared through Islamic religious requirements (Joassart- Marcelli et al. 2017; Zulfakar, Anuar, \& Ab Talib, 2014). Therefore, to accommodate these consumers, Canadian merchants seek out these products and deliver them to the marketplace (Moffat, Mohammed \& Newbold, 2017). Providing culturally appropriate food products to recently arrived refugees, especially for those who live in food deserts where major supermarket chains tend to ignore becomes important to ease settlement challenges of newcomer immigrants and refugees.

Mead, et al, (2010) discusses how one of the most important parts of integration is encouraging refugees to adopt more nutritionally sufficient diets, as well as encouraging them to adapt food from other cultures. Providing nutritional information in non-official languages becomes an imperative to ease shopping stress and confusion for refugees with no experience in Canadian supermarkets and who are seeking familiar foods in an unfamiliar food environment (Joassart-Marcelli et al. 2017; Moffat, Mohammed \& Newbold, 2017). This confusion leads newcomer refugees to purchase inadequate food, which is detrimental to their food security and overall health and well-being. In addition, Soo (2012) states cultural food is an essential reminder 
of home to newcomer refugees. Preparing and eating certain foods generate a sense of comfort, reduce time, and distance between home and an immigrant's current destination (Joassart- Marcelli et. al. 2017).

Some scholars have discussed how newcomers tend to have trouble adjusting to the common food tastes in their new country. In Moffat, Mohammed \& Newbold's study (2017), one of participant stated: "due to changes in the quality of available food in their new country, they are no longer enjoying eating" (p. 23). Compared to their familiar food tastes back home, they do not like to eat strange-tasting food, even if it is healthy-particularly among refugees' children, who are more finicky around experiencing unfamiliar food tastes.

Furthermore, in terms of food preferences, there are interesting factors that affect outerand inner-family dynamics for refugees. Tensions can arise among newcomer parents and their children when it comes to taking food outside of the home - refugees and immigrants often feel uncomfortable taking homemade food to school or workplaces, because of the fear that they may become the subject of jokes, shaming, and segregation (Joassart-Marcelli, et. al. 2017; Moffat, Mohammed \& Newbold, 2017; Soo, 2012). Such lesser-considered aspects of food insecurity affect the sense of social belonging, mental health, and overall quality of life for refugees. Overall, newcomer refugees face challenges to consume appropriate culturally acceptable food. 


\section{Challenges for Accessing Culturally Acceptable Foods for Refugees:}

All the ready-to-eat food I found to be unhealthy here. The frozen foods are salty and full of preservatives and dye. Fast food (is) too oily and nothing is fresh about the meat... In Colombia we cook everything from scratch. My mom goes shopping every day, buys everything fresh and then cooks them. It is really something new here and you have to adjust (Vahabi and Damba, 2013).

- Colombian refugee in Canada

Food plays a central role in human life as a primary source of nourishment. However, what people eat is also culturally defined. In the previous section, I reviewed the socio-economic factors behind higher incident of food insecurity among refugees. In this section, I will focus on challenges such as language proficiency, distance to food stores, lack of affordable housing, and problems with the food bank system for accessing culturally acceptable foods for refugees.

Food brings people together, providing opportunities for social connection, memories and attachment to people, places, spaces, and cultures (Koc, Soo \& Liu, 2015; Food Bank Canada, 2011). Likewise, people have a similar level attachment to their food, as certain foods remind them all these bonds with others and other places. Upon arrival to a new country, immigrants and refugees bring their food culture with them (Adekunle, Cidro, \& Filson, 2015). The distance from their past connections create nostalgia and familiar cultural practices and environments that help them reduce their earning and eases the pressures of adjustment into a new culture.

Often these cultural attachments are endorsed by food taboos, cultural restrictions imposed on individuals by their communities. Zulfakar, Anuar, \& Ab Talib, (2014), for example show how the Islamic religious rules of eating Halal is considered important for practicing Muslims. Muslim refugees do not want to eat non-Halal food, even if it is readily available, because of the cultural and religious restrictions (Joassart-Marcelli, 2017; Zulfakar, Anuar, \& Ab Talib, 2014).

\subsection{Language Proficiency}

"Back home, grocery shopping is a daily routine that offer the opportunity for social interaction with other people. Here I feel isolated and depressed as I do not speak the language and cannot go out to talk to others" (Vahabi and Damba, 2013).

The language barrier may in fact be the most important factor that contributes to 'food accessibility' amongst refugees. Language is one of the biggest predictors of labour market success among newcomer refugees (Wilkinson and Garcea, 2017). Upon arrival to Canada, those who 
speak English or French are able enter the labour market — whereas those who do not speak English or French face many problems in terms of integration. Refugees who have lack of English and/or French language capability face many problems, including the most basic tasks such as shopping or inquiring about food items at a grocery store (Ambtman \& Ali, 2009).

Some scholars argue that most refugees come from war-zone countries have had their education interrupted and tend to have problems in communicating in official languages. This makes it hard for them to read food labels and comparing prices of food items (Wilkinson and Garcea, 2017; Vahabi and Damba, 2013).

In some instances, differences in cultural norms in food shopping can also cause challenges for refugee families. For instance, many refugees consider shopping for groceries is a primarily activity for women. However, in Canada, refugee women often face communication challenges, while grocery shopping without the proper language skills make them feeling uncomfortable in their new home (Ambtman \& Ali, 2009). Many of these women were socializing while shopping in their home country and consider shopping as a form of community engagement. Communication and transportation difficulties disempowers refugee women and may lead to their isolation.

\subsection{Distance}

Even when refugees find a grocery store or market that carries their culturally familiar foods, the long distances from these ethnic and cultural food stores is another challenge. Most recently arrived refugees faces lack for private transportation and they must rely on alternatives to help them with food shopping (Wiig and Smith, 2009; Ambtman \& Ali, 2009). According to Joassart-Marcelli et al. (2017), large ethnic stores or supermarkets are normally far from newcomers' neighborhoods and are primarily used by consumers who have their own private vehicle and are planning to purchase groceries for a week or more (Wiig and Smith, 2009). Ambtman \& Ali (2009) argues that most of the time, major grocery outlets are located in areas difficult to access by public transportation. As such, refugees worry that they may get lost, because of difficulty of understanding signs and directions - especially in the beginning of their arrival.

When a refugee is in a precarious situation, they tend to buy food in small quantity, such

as one meal or one-day food at a time, which makes the bulk buying inaccessible to them (Zachary et al., 2013). In most cases, the unstable economic situation for newcomer refugees also does not 
enable them to travel long distances to purchase food for a week or a month, especially for those who do not have proper facilities at home for storage or cooking (Joassart-Marcelli et al., 2017).

In addition, the local convenience stores or gas stations that are accessible only offer limited items of food in small containers, priced by package or unit, which is more expensive than normal stores (Joassart-Marcelli et al., 2017). Regardless of transportation mode, the high prices of gasoline also challenge newcomer refugees shopping, because it could influence the food prices (Wiig and Smith, 2009). In these situations, people tend to spend too much time frequenting several stores in search of better price deals (Adekunle, Cidro, \& Filson, 2015).

As it is discussed that recently arrived refugees also have lower income than other immigrant groups and native-born Canadians. Skerrit (2013) and Martin (2012) discuss how this lack of purchasing power plays out in their studies of refugees in Winnipeg, in terms of food insecurity. Major grocery chains ignore, or even close their operations in lower-income areas, identified as 'food deserts' where many refugees find homes upon arrival because of the risks of operating in poverty-stricken neighborhoods (Joassart-Martelli, et al. 2017). Adekunle, Cidro, \& Filson, (2015) states that even if they operate, in low-income neighborhoods, the grocery stores do not keep fresh and wide varieties of foods. As such, whenever refugees have challenges of low-income and lack of access to culturally appropriate food, they tend to decrease their food consumption and look for ways to access cheap food, instead of purchasing the appropriate food that helps retain their health. Adekunle, Cidro, \& Filson, (2015) argues that this effect of poverty has led to even more social problems for refugees. Crime, safety issues, and racial discrimination directly contribute to food insecurity, as grocery store owners become far less interested in opening an outlet in the neighborhood.

\subsection{High cost of living combined with lack of affordable housing:}

"The job pays little and near our place they are not that many big food stores like No Frills [A large discount supermarket]. We do not have a car and have to take the TTC [Toronto Transit Commission] for transportation and that is costly when you have to pay for rent and other bills" (Vahabi and Damba, 2013).

The successful integration of refugees into their new society requires fulfillment of several basic needs such as food and shelter. Since mid-1990s, funding cuts in social housing has been creating major challenges for affordable and suitable housing for lower income people living in major metropolitan areas where majority of newcomer immigrants and refugees reside (Paradis et al. 2010). Access to affordable housing is the first step on integration of newcomer refugees, 
especially in high-cost cities such as Toronto, Vancouver, Calgary, and Montreal (Murdie, \& Logan, 2012; Kissoon, 2010). As the criteria for admission to Canada required for immigrants such as education, language and other assets are not required for the refugees; they face many challenges on finding employment and housing in Canada (Shan, 2019). Suitable housing is not just important for basic shelter, but for finding a sense of community - a neighborhood in which one can find a social network, easy to access labour market and employment opportunities, as well as public social spaces and availability of green parks or more easily integrate into Canadian society (Rose, 2010).

Research indicates that refugees, particularly in the initial stages of their settlement experience, overwhelmingly reside in rental housing (Edmonston, 2016). In developed cities such as Toronto or Montreal, it is difficult for newcomer refugees to find affordable housing due to their large family size (Ennab, 2017). At the first stage of the application process, most landlords look at family size and income levels before deciding to rent their apartment to the potential tenants, which disadvantages refugees considerably in the selection process (Sherrel, 2009; Kissoon, 2010)

Murdie \& Logan (2012) highlights that Canada is "the only G8 country that currently doesn't have a national housing policy"-rather, it has different incentive programs to homeowners but not renters (p. 362). Part of the issue with housing is based on a private market that has been resulting in substantial decrease on the availability of affordable rental properties.

By having limited social support and low incomes, refugees experience more challenges compared to earlier-arrived immigrants on finding affordable housing (O'Neill, et al. (2019). If they cannot find affordable housing on their own, they must wait for formally subsidized housing, which can take years (Ambtman \& Ali, 2009). During this waiting period, newcomer refugees live in large apartment complexes in downtown neighborhoods (Murdie, 2010) with limited outdoor playing opportunities. As a result, many refugee children tend to have less physical activity, watching television or playing video games and end up gaining weight (Sherrell, 2009). Additionally, compared to other immigrants and the general Canadian population, refugees spend an inordinately bigger portion of their income on shelter, and thus little money remains for other essentials such as food and clothing (Murdie, 2010).

In some cases, refugees also experience discrimination and prejudice in rental housing markets based on their race and culture background (Murdie, \& Logan, 2012; Murdie, 2010). To address these challenges in Canada, each province has its own tenant protection policy. Soo (2012) 
highlights that Ontario introduced its Tenant Protection Act in 1998, stopping "landlord [who] could [previously] more easily raise rents," which had led to a 20\% spike in rent for Ontarians (p. 17). Clearly, much more government-subsidized housing is a promising solution to these housing issues, offering considerable benefits such as location, affordable rent, and access to services (Rose, 2010).

It is important to study the different challenges that refugees face in different Canadian cities. Adekunle, Cidro, \& Filson, (2015) states that in Winnipeg, most refugee families rely on social assistance during the first five years of their arrival, due to language and employment challenges. Because of family size and tenancy rules and regulations, they are not eligible to rent small-size apartments, yet they cannot afford to apply for big apartments, which leaves them in a real housing crisis (Sherrell, 2010). Such problems force them to find apartments far from schools and business hubs, which makes it considerably harder to go for grocery shopping. In Winnipeg, which does not have very robust public transit systems - particularly in the winter season refugees rely on whatever they have at home, which means less healthy and fresh food.

\subsection{Limited Effectiveness of Food Banks}

I have been using the food bank, but I find when I go home and check what they [food banks] give me, I have to throw away half or more of the food because they are expired. The cans are expired, and I have health problems. I already have diabetes and some cholesterol issues, so I cannot use the food. I cannot use the food bank. -Colombian women (Moffat, Mohammed \& Newbold, 2017)

Overall, most newcomer refugees experience challenges in food availability because of lowincome and high food costs, as well as significant cultural differences. So many non-profit organizations across Canada provide free meals and snacks to low-income households on a regular basis (Food Banks Canada, 2011). Food banks are the frontlines of charitable food assistance organizations that support immigrants and refugees during the time of need (Miller, 2016). Bazerghi, McKay, \& Dunn, (2016) indicates that due to low-income, high cost of rents, and high rates of unemployment, food bank use is higher among newly arrived refugees in Canada. Yet

food banks are not completely accessible especially to newly arrived refugees who do not have proper government-issued identification papers (Soo, 2012). Tarasuk, Mitchel, \& Dachner, (2014) states that food bank statistics do not accurately reflect the level of food insecurity as many food insecure people, including some of the refugees and newcomer immigrants may not be among the 
beneficiaries. In addition, Vahabi and Damba (2013) point out that food banks have limited food items and they are open during limited hours. Moffat, Mohammed \& Newbold (2017) adds that refugees commonly complain about poor quality or inappropriate foods that prevented them from using food bank other than in truly desperate circumstances.

Despite such limitation, however, food banks provide an important service to refugees as a source of emergency assistance. Miller (2016), for example, refers to the efforts of the Ottawa Food Bank that registered 125 refugee families and provided groceries to over 737 refugees who were facing food insecurity.

One of the major problems with food banks in Canada is their failure to provide culturally familiar and traditional foods to newcomer refugees (Vahabi and Damba, 2013). Devout Muslim refugees, for example, were reported to avoid using food banks due to lack of halal foods (Zulfakar, Anuar, \& Ab Talib, 2014). Their limited income and refusal to rely on food banks, increases their vulnerability to food insecurity. However, even with their limited ability to fully service the needs of refugees, these organizations do help recently arrived refugees through difficult times. As such, it remains crucial to make food banks and other sources of community food security organizations to be more accessible to newcomer refugees in Canada. 


\section{Conclusion:}

Food security is an important concern for many newcomer immigrants and refugees. While in recent years more attention has been given to the food security concerns of newcomer immigrants, not much has been written in terms of the food security concerns of the refugees. This study provided an exploratory review of the literature on the food insecurity concerns of the refugees in Canada by focusing on the recent publications between 2009 2019 on this topic. This chapter will provide a review of my key findings regarding food insecurity among refugees living in Canada, provide some policy recommendations offered by the literature reviewed and summarize the limitations of my research.

After reviewing several academic articles, I recognized that newcomer refugees in Canada suffer higher incidents of food insecurity than immigrants and Canadian born. Coming from precarious living conditions in refugee camps or transition countries, refuges tend to have bigger vulnerability in terms of nutritional adequacy and health problems. Continuation of this precarious existence in Canada, due to lack of employment, or limited and temporary employment, inadequate income, insufficient social supports not only prolong their agony, but worsens their long term physical and mental health conditions.

A second very important issue is that, food security in the case of refugees need to be perceived more than availability and accessibility of safe and nutritious foods, but it also necessitates provision of culturally acceptable foods. After many months, or even years of living precariously, refugees tend to have a much more challenging settlement process. Even those who may feel safer and more comfortable in Canada. Many refugees still feel that they have been separated from their homeland by unfortunate circumstances and they feel nostalgic, for their culture and communities. Culturally familiar foods become a key factor in providing them some comfort and making them feel at home. Unfortunately, access to culturally familiar foods may not be possible in many instances. Lack of local language proficiency, high cost of housing, distance from cultural food, and other cultural barriers increase the negative effects of such challenges and put refugees in situations of stress and anxiety in their new home. Improving availability and accessibility of safe, nutritious and culturally acceptable foods for refugees need to be seen as both a food security as well as a settlement priority.

Food availability and accessibility both are the main pillars of food security. Soo (2012) has highlighted how food in available in many different varieties in all supermarkets; yet due to 
less freshness - with lots of frozen and processed food in Canada-newcomers do not trust these unfamiliar brands and thus find difficulty in purchasing specific cultural food items (Moffat, Mohammed \& Newbold, 2017).

Food accessibility presents both physical and economic solutions at the household level (De Haen, Klasen, \& Qaim, 2011). Physical access to food is regulated by the existence of food at the national and regional level, while economic access to food is related to the purchasing power of the individual household. Because of inadequate income, access to food is a great challenge for newcomer refugees. Their low socio-economic situation creates significant barriers to access food, particularly culturally acceptable food.

The evidence from other studies indicates that most refugees expressed frustration regarding culturally acceptable food, or they often find themselves in a food deserts in Canada. Because of high rates of unemployment, poverty, crime, and safety issues - newcomer refugees face many problems that complicate their resettlement process (Carter \& Osborne, 2009). When refugees want to find employment, despite their comparable education and work experience, they often face difficulty having their credentials recognized by employers. They thus must accept lowincome jobs, which creates issues in terms of living costs in urban areas (Soo, 2012, p. 14).

Discrimination and prejudices are other cultural issues that create barriers to newcomer refugees entering the Canadian job market (Rudenko, 2012).). The barriers to food security includes lack of sufficient employment opportunities, insufficiency of government assistance, higher costs of food, housing and transportation, insufficient child care support, challenges of languages proficiency, lack of knowledge about available services and other food provisioning options, gender bias within refugee households and time restraints. Compared to other challenges, insufficient income has been identified as a major barrier to access sufficient, healthy and adequate food.

Access to culturally acceptable foods is an important component for identity and membership in a multicultural society. Joassart-Martelli et al. (2017) state that the maintenance of culturally familiar foods for newcomer refugees requires recognition of their unique identity and addresses the cultural value of their food practices. Studies on the process of refugee integration indicate that availability of culturally familiar foods helps refugees to feel a sense of belonging and "feel more at home" in their new country (Soo, 2012). For refugees shopping in Canadian superstores are incredible stressful and confusing (Zulfakar, Anuar, Ab Talib, 2014). These people 
often struggle to access familiar food. Such confusion often contributes to newcomer refugees' purchases, that they reduce it to inadequate quantities, which is detrimental to their food security and overall health and well-being.

After my review of the literature about food availability and accessibility, I have determined that one the major barriers leading to confusion and frustration among refugees during the settlement process is lack of language proficiency. Language proficiency is the most important barrier that contributes to food security among newcomer refugees. Language is one of the most significant indicators of labour market success among newcomer refugees (Wilkinson and Garcea, 2017; Vahabi and Damba, 2013).

Refugees are often coming from war-torn countries, where education has been interrupted, so upon arrival a large segment of refugees do not have proficiency in English or French languages. Those who can speak English or French are more quickly able to enter the labor market, compared to those who do not know English; even they have higher education levels. In their attempt to find their co-ethnic people who share the same language and culture many newcomers end up moving to ethnic enclaves where they also receive advice in finding affordable housing or jobs. However, ethnic enclaves are not conducive to learning or improving their language skills in official languages (Rose, 2010).

Women primarily do grocery shopping back home, but in Canada it is often difficult for refugee women to shop because of language difficulties. Without language proficiency, women do not have the tools to ask for specific cultural foods from storeowners or potential alternatives even if they were available. To ease this, increasing access to language literacy classes for both men and women, and providing day care for those who have younger children at home would be essential not only for successful integration but also for food security.

Lack of cultural and traditional food in Canadian supermarkets is an important barrier that newcomer refugees face. Even though these foods are available in most Canadian stores, many refugees with limited budget cannot afford them. For those who follow certain religious practices are also not comfortable eating some foods. Often, ethnic stores can provide culturally familiar foods for refugees but because of their limited purchasing power, they tend to be more expensive than major chain stores.

Transportation is another barrier for newcomer refugees in accessing culturally familiar foods. Long distances from food outlets or supermarkets make them hard to reach by those who 
have limited access to transportation. Most of the time, food outlets and supermarkets are not close to their apartments and upon arrival, refugees do not have enough money to buy a car or pay for insurance. Shopping for basic needs-particularly in the winter becomes difficult for those who rely on public transit. Sometimes, it is also difficult for newcomers to understand the public transportation system, especially at the beginning of arrival. They worry that they may get lost or go to the wrong place. Buying in bulk to benefit from lower prices is also not an option for those with limited storage space or funds (Ambtman and Ali, 2009).

Such barriers may force newcomers to buy food at high prices from convenience stores or use public transportation, which is often expensive when only purchasing groceries for one or two meals at a time. Wiig and Smith (2009) states that at the beginning, newcomer refugees rely on alternatives to help them with food shopping - particularly in small communities that live far from large ethnic stores or supermarkets. In such precarious situations, refugees tend to purchase food in small quantity. Upon arrival, it is necessary that settlement agencies or community workers help newcomer refugees to find appropriate ethnic stores and help them to learn how to navigate public transportation.

With respect to all barriers and challenges, shelter is the most important issue for newcomer refugees in all regions of Canada. Many scholars states that successful integration of refugees into a new society is based on their fulfillment of housing, basic needs (i.e., healthy food and clothing), and integration into the labour market. Since the mid-1990s cuts in investment in public housing projects lowered the availability rate of affordable housing for people with lower income (Murdie, 2010). Provincial and local governments and private sponsors do provide housing and basic needs support, but for asylum seekers these supports are not accessible. Most Asylum seekers suffer in terms of housing because landlords ask for proof of income and credit report, which is difficult for them to provide. Rose (2010) states that compared to the general Canadian population, refugees spend an inordinately big portion of their income on shelter and leave little budget for other basic essentials such as food and clothing.

In addition, it is also noted that most refugee families are bigger than the average Canadian families, and after a certain period of time government and the sponsored family cannot continue helping them. Most of them rely on government social assistance- 'welfare'—or they can only find a part-time job. Therefore, it is important that government need to review immigration and settlement policies to assure that upon arrival refugees will receive assistance for adequate 
employment and housing. The federal and provincial governments thus need to develop polices for providing newcomer refugees with suitable and affordable housing support, and have different robust programs.

Across Canada, food banks have been providing food to low-income households such as newcomer refugees and other Canadians on a regular basis. Most refugees have large families and due to their low income, they cannot properly support themselves, so they rely on food banks. Several studies state that food banks in Canada fail to provide newcomer refugees with good quality, adequate cultural and traditional food (Vahabi and Damba, 2013; Tarasuk, Mitchel, \& Dachner, 2014; Tarasuk, Dachner, \& Mitchell, .2019; Moffat, Mohammed \& Newbold, 2017). Because of poor quality and culturally inappropriate foods, refugees end up using food banks other than in truly desperate circumstances. Food banks also have limited opening hours so that newcomer refugees struggle to gain access during these times. Food banks especially in big cities need to adjust their distribution strategies to provide more culturally appropriate foods.

In the end, I want to add some recommendations that the federal and provincial governments and other settlement organizations need to adapt in order to addressing the food insecurity problems among refugees in Canada.

1) The Federal government needs to increase funding sources to settlement agencies to conduct nutrition and safety programs and improve local language training for newcomer refugees.

2) The Provincial governments should help refugees on getting adequate employment and affordable housing upon arrival.

3) The settlement and ethno cultural organizations should develop strategies to help newcomers' childcare programs and provide cooking classes opportunities for parents, particularly for those women and girls who are not participating in social activities. If possible, food bank should increase ethnic food items and working hours.

4) Public and private schools should promote cultural food and encourage students to bring their cultural food and while eating, allow them to heat it.

It is crucial that settlement agencies and business owners understand the cultural values, concerns, and food ways of newcomer refugees in their new home. This research demonstrates that newcomer refugees suffer higher rates of food insecurity. Unfortunately, sample-based surveys or even food banks surveys do not provide enough insights on the extent of food insecurity 
among refugees. More targeted research is needed to identify the most vulnerable communities and the reasons for their vulnerabilities. This exploratory research provided some necessary insights. 


\section{Limitation:}

Initially I planned to conduct this research among newcomer refugees' particularly Afghan refugees and include a number of interviews with Afghan refugees living in Toronto, and use qualitative and quantitative mixed method. Due to time concerns, and potential difficulties in completing ethics review that is needed for this process, I ended up limiting my research to a literature review.

In my review of the literature, I also wanted to gain insights on the causes and consequences of food insecurity within the Canadian context and among immigrants which needed to follow more targeted review of the literature on conditions of food insecurity among immigrants and native-born Canadians. My focus was just on newcomer refugees who recently arrived in last decade from 2009 2019. So, further research is required to fully understand the perceptions of food insecurity among Canadians, particularly indigenes people in Canada who are really facing challenges, find the factors causing them, and recommend evidence-based solutions to federal and provincial government and other related organizations. Due to language limitations, I limited my review to only English language and could not review research in French on immigrants and refugees in Canada. 


\section{References:}

Adekunle, B., Cidro, J., \& Filson, G. (2015, December). The Political Economy of Culturally Appropriate Foods in Winnipeg: A Case of Refugee Path Immigrants (RPIs). Report by the Canadian Centre for Policy Alternatives (CCPA), Manitoba Office.

Ambtman, R., \& Ali, R. (2009, April). Healthy lifestyles for newcomers in Manitoba. A report for healthy living manitoba and the public health agency of canada. Winnipeg.

Bazerghi, C., McKay, F. H., \& Dunn, M. (2016). The role of food banks in addressing food insecurity: A systematic review. Journal of Community Health, 41(4), 732-740.

Behjat, A. (2012). A comparative investigation in measuring food access: Food deserts in urban setting (Master's thesis).

Bidwell, S. (2009). Food Security: A review and synthesis of themes from the literature. Paper prepared for Programme Area Four Community and Public Health Christchurch, Canterbury District Health Board. Retrieved from http://www.ana.org.nz/documents/ FoodSecurityReview_090827.pdf

Carter, T. S., \& Osborne, J. (2009). Housing and neighborhood challenges of refugee resettlement in declining inner city neighborhoods: A Winnipeg case study. Journal of Immigrant \& Refugee Studies, 7(3), 308-327.

Centre for Studies in Food Security. (2012). Food security defined. Retrieved from https://www.ryerson.ca/foodsecurity/

Citizenship and Immigration Canada. (2016). Facts and figures 2015-immigration overview: permanent residents. Government of Canada, Ottawa.

Cowart, M. T. (2012). Refugee Resettlement and Second Language Acquisition. English Language Learners in 21st Century Classrooms: Challenges and Expectations.

D'Souza, A., and Jolliffe, D. (2013). Conflict, food price shocks, and food insecurity: The experience of afghan households. Food Policy, 42(Complete), 32-47.

doi:10.1016/j.foodpol.2013.06.007

De Haen, H., Klasen, S., \& Qaim, M. (2011). What do we really know? Metrics for food insecurity and undernutrition. Food Policy, 36(6), 760-769.

Edmonston, B. (2016). Canada's immigration trends and patterns. Canadian Studies in Population, 43(1-2), 78-116. 
Ennab, F. (2017). Being Involved in Uninvolved Contexts: Refugee Parent Involvement in Children's Education. Canadian Centre for Policy Alternatives.

Food Banks Canada. (2011). Hunger Count: A comprehensive report on hunger and food bank use in Canada, and recommendations for change. Retrieved from http://www.foodbankscanada.ca/ getmedia/dc2aa860-4c33-4929-ac36fb5d40f0b7e7/HungerCount-2011.pdf.aspx

Food Secure Canada, (2017). Building a health just and sustainable food system: food secure canada's recommendations for a food policy for canada, Retrieved from; https://foodsecurecanada.org/sites/foodsecurecanada.org/files/attached_files/policy_brief_a food_policy_for_canada_sept_28_by_fsc.pdf

Hammelman, C., \& Hayes-Conroy, A. (2015). Understanding cultural acceptability for urban food policy. Journal of Planning Literature, 30(1), 37-48.

Health Canada. (2010). Household Food Insecurity in Select Provinces and the Territories in 2009-2010. Retrieved from http://www.hcsc.gc.ca/fnan/surveill/nutrition/commun/insecurit/key-stats-cles-2007-2008-eng.php

Huang, E. (2014). Assessing the barriers and facilitators to food security that influence dietary changes among refugees (Doctoral dissertation).

IRCC (2018). "Refugee Operation Instruction and Guidelines" Government of Canada, Ottawa, retrieved from; https://www.canada.ca/en/immigration-refugeescitizenship/corporate/publications-manuals/operational-bulletins-manuals.html

Joassart-Marcelli, P., et al., (2017). Ethnic markets and community food security in an urban “food desert". Environment and Planning A, 49(7), 1642-1663.

Kissoon, P. (2010). An uncertain home: Refugee protection, illegal immigration status, and their effects on migrants' housing stability in vancouver and toronto. Canadian Issues, 64.

Koc, M., Soo, K. and Liu W.L. (2015). Newcomer Food Security and Safety in H. Bauder and J. Shields (eds.) Immigrant experiences in North America. Toronto: Canadian Scholars' Press, pp. 292

Kohnen, C. A. (2014). Household food insecurity among recent immigrants to canada: a quantitative analysis.

Lane, G., Nisbet, C., \& Vatanparast, H. (2019). Food Insecurity and Nutritional Risk among Canadian Newcomer Children in Saskatchewan. Nutrients, 11(8), 1744. 
Martin, M. (2012). End of an oasis: neighborhood's food desert grows; A depressing finale for a grocery store that began during the Great Depression and was a lifeline in one of the city's poorest communities.

Mathew, V. N. (2014). Acceptance on halal food among non-Muslim consumers. ProcediaSocial and Behavioral Sciences, 121, 262-271.

Maynard, M., et al., (2019). The Experience of Food Insecurity among Immigrants: a Scoping Review. Journal of International Migration and Integration, 20(2), 375-417.

Mead, E., et al. (2010). Healthy food intentions and higher socioeconomic status are associated with healthier food choices in an Inuit population. Journal of human nutrition and dietetics, 23, 83-91.

Medrano Chavez, A. L. (2015). Dietitian's perceptions, knowledge and attitudes regarding their role in the assessment of food insecurity in Alberta.

Miller, J. (2016, May 06). Syrian refugees relying on food banks; little cash but 'very grateful'. The Ottawa Citizen, Retrieved from

http://ezproxy.lib.ryerson.ca/login?url=https://search-proquestcom.ezproxy.lib.ryerson.ca/docview/1787255785? accountid $=13631$

Moffat, T., Mohammed, C., \& Newbold, K. B. (2017). Cultural dimensions of food insecurity among immigrants and refugees. Human Organization, 76(1), 15-27. doi:http://dx.doi.org.ezproxy.lib.ryerson.ca/10.17730/0018-7259.76.1.15

Murdie, R. (2010). Precarious Beginnings: The Housing Situation of Canada's Refugees. Canadian Issues, 47.

Murdie, R. A., \& Logan, J. (2012). Precarious housing \& hidden homelessness among refugees, asylum seekers, and immigrants: Bibliography and review of Canadian literature from 2005 to 2010. CERIS.

Oda, A. Hynie, et al., (2019). Differences in Self-Reported Health and Unmet Health Needs between Government Assisted and Privately Sponsored Syrian Refugees: A Cross-Sectional Survey. Journal of immigrant and minority health, 21(3), 439-442.

O'Neill, T. et al. (2019). The Nepali-Canadian Living Standards Survey: Newcomer Incorporation in the Greater Toronto Area. Canadian Ethnic Studies, 51(1), 69-88.

Paradis, E., et al. (2010). Homelessness and Housing among Status Immigrant, Non-Status Migrant, and Canadian-Born Families in Toronto. Canadian Issues Themes Canadiens: Newcomer'Experiences of Housing and Hmelessness in Canada, 36-40. 
Preston, V., et al., (2011). Precarious housing and hidden homelessness among refugees, asylum seekers, and immigrants in the Toronto Metropolitan Area. CERIS Working Paper No. 87. Retrieved from http://mbc.metropolis.net/assets/uploads/files/

Precarious_Housing_Toronto_study.pdf

Qadeer, M., Agrawal, S. K., \& Lovell, A. (2010). Evolution of ethnic enclaves in the toronto metropolitan area, 2001-2006. Journal of International Migration and Integration, 11(3), 315-339.

Reiter, B. (2017). Theory and methodology of exploratory social science research. International Journal of Science and Research Methodology, 5(4), 129.

Riches, G. (Ed.). (2016). First world hunger: Food security and welfare politics. Springer.

Rose, D. (2010). "The Housing Situation of Recent Immigrants to Montréal in Comparative Metropolitan Perspective: Contrasts and Convergences. " Canadian Issues/Thèmes Canadiens (Newcomer's Experiences of Housing and Homelessness in Canada). Montréal: Association for Canadian Studies, Fall 2010: 73-78. (http://canada.metropolis.net/publications/aec_citc_fall2010_e.pdf)

Rudenko, M. (2012). Canadian Experience” and Other Barriers to Immigrants' Labour Market Integration: Qualitative Evidence of Newcomers from the Former Soviet Union. Retrieved from Ryerson University Digital Commons.(Paper 1676).

Simich, L., Este, D., \& Hamilton, H. (2010). Meanings of home and mental well-being among Sudanese refugees in Canada. Ethnicity \& health, 15(2), 199-212.

Shan Rachel, (2019). Socio-economic analysis, housing needs and conditions; recent refugee housing conditions in canada, retrieved from https://www.cmhc-schl.gc.ca/en/data-andresearch/publications-and-reports/socio-economic-analysis-recent-refugee-housingconditions-canada

Sherrell, K. Immigrant Services Society of British Columbia (ISSofBC).(2009). At home in Surrey?: The housing experiences of refugees in Surrey, BC, Final Report.

Sherrell, K. (2010). Legal status, place, or something else? the housing experiences of refugees in winnipeg and vancouver. canadian issues/thèmes canadiens.

Shiva Vandana, (2013). Food: a basic human need, and right; partnership for stong community. Retrieved from; http://www.pschousing.org/news/food-basic-human-need-andright

Skerrit, Jen. (2013 ). City turns its back on 'food deserts': Retrieved from: https://www.winnipegfreepress.com/local/city-turns-its-back-on-food-deserts201389591.html 
Soo, Kristen, 2012. Newcomers and food insecurity: a critical literature review on immigration and food security. a Major Research Paper presented to Ryerson University; Master of Arts in the Program of Immigration and Settlement Studies. Toronto, Ontario, Canada,

Sundaram, J. K. (2012). The State of Food Insecurity in the World: Economic Growth is Necessary but Not Sufficient to Accelerate Reduction of Hunger and Malnutrition. Food and agriculture organization of the United nations (FAO).

Tarasuk, V., Mitchel, A., \& Dachner, N. 2014). Household Food Insecurity in Canada 2014.Toronto: Tarasuk, Dachner \& Mitchell University of Toronto.

Tarasuk V, Li N, Dachner N, Mitchell A. (2019). Household food insecurity in Ontario during a period of poverty reduction, 2005-2014. Canadian Public Policy. doi: https://doi.org/10.3138/cpp.2018-054.

Tarraf, D., Sanou, D., \& Giroux, I. (2017). Immigration and Food Insecurity: The Canadian Experience-A Literature Review. People's Movements in the 21st Century: Risks, Challenges and Benefits, 37.

Teixeira, C. (2009). New immigrant settlement in a mid-sized city: a case study of housing barriers and coping strategies in Kelowna, British Columbia. The Canadian Geographer/Le Géographe Canadien, 53(3), 323-339.

Trinidad, A. M., Camden, H., \& Coleman, A. (2015). Improving access to food systems among communities of color: A Food Justice Issue.

Weaver, L. J., \& Hadley, C. (2009). Moving beyond hunger and nutrition: a systematic review of the evidence linking food insecurity and mental health in developing countries. Ecology of food and nutrition, 48(4), 263-284.

Wiig, K., \& Smith, C. (2009). The art of grocery shopping on a food stamp budget: factors influencing the food choices of low-income women as they try to make ends meet. Public health nutrition, 12(10), 1726-1734.

WHO. (2015). Trade, foreign policy, diplomacy and health. Retrieved from http://www.who. int/trade/glossary/story028/en/

UNHCR, (2018). What is a refugee, Retrieved from; https://www.unrefugees.org/refugeefacts/what-is-a-refugeel

UNHCR Canada (2018). Resettlement handbook, by the government of Canada, Retrieved from; https://www.unhcr.org/3c5e55594.pdf 
Vahabi, M., \& Damba, C. (2013). Perceived barriers in accessing food among recent Latin American immigrants in Toronto. International journal for equity in health, 12(1), 1.

Vahabi, M., et al., (2015). Challenges in recruiting hard-to-reach populations focusing on Latin American recent immigrants. International Journal of Human Rights in Healthcare, $8(1), 36-44$.

Wilkinson, L., \& Garcea, J. (2017). The economic integration of refugees in Canada: A mixed record? Washington, DC: Migration Policy Institute.

Zulfakar, M. H., Anuar, M. M., \& Ab Talib, M. S. (2014). Conceptual framework on halal food supply chain integrity enhancement. Procedia-Social and Behavioral Sciences, 121, 5867.

Zurba, M., Islam, D., Smith, D., \& Thompson, S. (2012). Food and healing: an urban community food security assessment for the North End of Winnipeg. Urban Research \& Practice, 5(2), 284-289. 